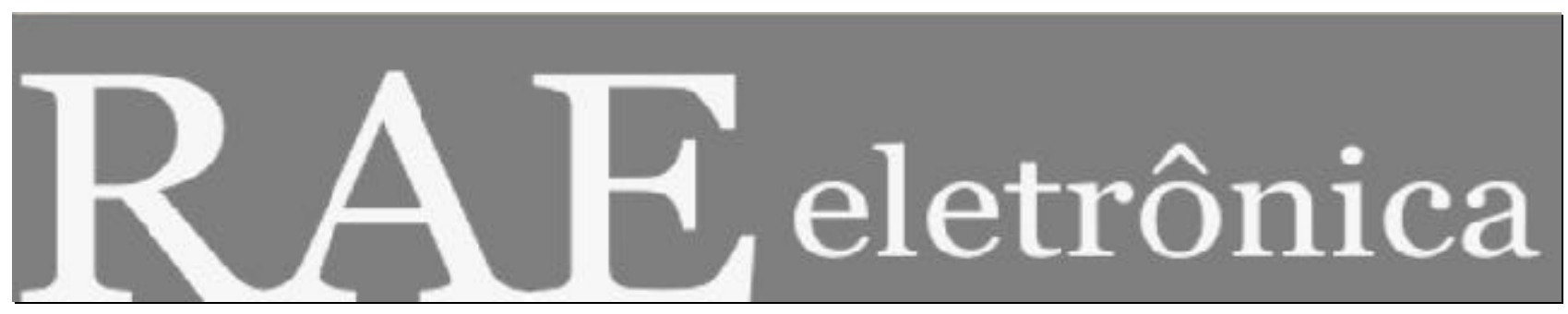

\title{
AS PRESSÕES AMBIENTAIS DA ESTRUTURA DA INDÚSTRIA
}

Por:

\section{Mônica Cavalcanti Sá de Abreu \\ Gregório Jean Varvakis Rados \\ Hugo Santana de Figueiredo Junior}

RAE-eletrônica, v. 3, n. 2, Art. 17, jul./dez. 2004

http://www.rae.com.br/eletronica/index.cfm?FuseAction=Artigo \&ID=1 832\&Secao=ESTRATÉGIA\& Volume $=3 \&$ Numero $=2 \&$ Ano $=2004$

CCopyright, 2004, RAE-eletrônica. Todos os direitos, inclusive de tradução, são reservados. É permitido citar parte de artigos sem autorização prévia desde que seja identificada a fonte. A reprodução total de artigos é proibida. Os artigos só devem ser usados para uso pessoal e nãocomercial. Em caso de dúvidas, consulte a redação: redacao@ rae.com.br.

A RAE-eletrônica é a revista on-line da FGV-EAESP, totalmente aberta e criada com o objetivo de agilizar a veiculação de trabalhos inéditos. Lançada em janeiro de 2002, com perfil acadêmico, é dedicada a professores, pesquisadores e estudantes. Para mais informações consulte o site $\underline{\text { www.rae.com.br/eletronica. }}$

RAE-eletrônica

ISSN 1676-5648

(C2004 Fundação Getulio Vargas - Escola de Administração de Empresas de São Paulo.

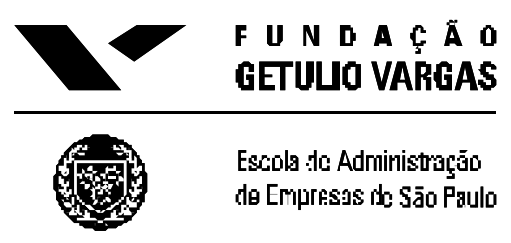




\title{
AS PRESSÕES AMBIENTAIS DA ESTRUTURA DA INDÚSTRIA
}

\section{RESUMO}

Este artigo revela como as pressões ambientais da estrutura da indústria influenciam a performance das empresas no mercado. Os resultados alcançados em uma pesquisa aos setores petroquímico, têxtil e de bebidas identificam o impacto ambiental, a legislação ambiental e as exigências ambientais das partes interessadas como as principais pressões ambientais da estrutura da indústria, que levam as empresas a adotarem condutas ambientais específicas. Dessa forma, a compreensão das pressões ambientais da estrutura da indústria permite que as empresas avaliem, de forma prática, seu posicionamento estratégico atual e definam qual a posição que desejam ocupar. No sentido de oferecer às empresas ferramentas mais completas de planejamento ambiental estratégico, este artigo apresenta também o desenvolvimento do modelo Estrutura-Conduta-Performance Ambiental (ECP-Ambiental). O modelo dita que a performance ambiental de uma empresa é o reflexo da conduta ambiental adotada, que por sua vez, depende da estrutura de mercado em que está inserida.

\begin{abstract}
This article shows how the environmental pressures of the industry structure end up influencing the business performance. The research was conducted with the petrochemical, the textile and the beverage sectors in Brazil and identifies the possible environmental impact of a business, the environmental legal system, and the demands from stakeholders as being the main environmental pressures upon businesses that influence their environmental conduct. Therefore, the understanding of the environmental pressures of the industry structure allows the businesses to evaluate, in a practical manner, their current strategic positioning and define their future positioning. In order to meet the business demand for strategic environmental planning tools, this paper also presents the model Environmental Structure-Conduct-Performance (Environmental - SCP). This model states that a business environmental performance is derived from its environmental conduct, which, in turn, depends on the market structure where the business operates.
\end{abstract}

\section{PALAVRAS-CHAVE}

Gestão ambiental, performance ambiental, indicadores ambientais, estratégia, estrutura da indústria.

\section{KEY WORDS}

Environmental management, environmental performance, environmental indicators, strategies and industry structure 


\section{ESTRATÉGIA - AS PRESSÕES AMBIENTAIS DA ESTRUTURA DA INDÚSTRIA \\ Mônica Cavalcanti Sá de Abreu - Gregório Jean VarvakisRados - Hugo Santana de Figueiredo Junior}

\section{AS TRANSFORMAÇÕES NO AMBIENTE COMPETITIVO}

Nas últimas décadas, as empresas têm assistido a transformações muito amplas em seu ambiente competitivo, calcadas na valorização das preocupações de caráter ambiental e social, além das econômicas. As empresas estão, portanto, sujeitas às mudanças nos valores e ideologias da sociedade $\mathrm{e}$ às pressões do ambiente externo à organização, que acabam por influenciar sua performance no mercado.

Paralelamente, as instituições governamentais e não-governamentais, a mídia, a sociedade civil e as instituições financeiras têm exposto os problemas ambientais da atividade produtiva e forçado as organizações a adotarem sistemas de gestão e controle da variável ambiental. Esses investimentos na área ambiental, antes simplesmente considerados como necessários, hoje devem ser vistos como estratégicos à atuação das empresas, gerando benefícios sociais, ecológicos e econômicos.

Nesse sentido, Elkington (1999) ressalta que o momento atual de revolução cultural exige que as empresas, muito mais que as organizações governamentais e não governamentais, estejam preparadas para se sentarem no "banco do motorista", guiando em direção ao desenvolvimento sustentável. Portanto, o salto da sustentabilidade teórica para a prática não é uma questão simples para as empresas, principalmente, as transnacionais, que são forçadas a pressionar sua cadeia de negócios, através dos seus fornecedores de produtos e de serviços. Essas pressões são seguidas por uma profunda mudança nas expectativas da sociedade, com reflexos no mercado de negócios.

Neste artigo é apresentado um modelo de avaliação da estratégia ambiental que preenche uma lacuna existente entre os modelos ambientais atuais e os de estratégia competitiva para análise da estrutura da indústria. Observa-se que os modelos ambientais (ABIQUIM, 2001; ISO 14001:1996; Norcia, 1996; Elkington, 1998, Rodriguez e Ricart, 1998) não permitem um ordenamento contínuo da performance ambiental entre diferentes empresas dentro da mesma estrutura da indústria. Portanto, não possibilitam inferir, sistematicamente, comportamentos ou condutas ambientais mais efetivas em relação a outras empresas.

Por outro lado, os modelos atuais de análise da estrutura da indústria, representados pelo modelo de Porter (Porter, 1980) e o ECP-Estrutura-Conduta-Performance (Scherer e Ross, 1990) avaliam a estratégia a ser adotada pela empresa examinando o potencial de geração de vantagens competitivas dada à natureza da indústria na qual ela compete e os seus próprios ativos e potencialidades. Nesses modelos, o único aspecto de desempenho considerado é o financeiro.

Sob o ponto de vista do modelo proposto, a performance ambiental de uma empresa é o reflexo da conduta ambiental adotada, que por sua vez, depende da estrutura de mercado em que está inserida. Este artigo se propõe a discutir as características ambientais da estrutura da indústria, oferecendo um quadro organizado das pressões ambientais, ditadas por meio da legislação ambiental, do impacto ambiental e das exigências amb ientais das partes interessadas. Essas características sempre estiveram presentes, todavia, não eram devidamente consideradas durante a análise da estrutura de mercado. 


\section{UM MODELO MAIS COMPLETO DE AVALIAÇÃO DA ESTRATÉGIA}

Porter (1980) afirma que a estrutura industrial tem uma forte influência na determinação das regras competitivas, assim como, nas estratégias potencialmente disponíveis para a empresa. As forças externas são significativas em sentido relativo, uma vez que afetam todas as empresas da indús tria. $\mathrm{O}$ ponto básico encontra-se nas diferentes habilidades das empresas em lidar com elas. $\mathrm{O}$ autor comprova que a intensidade da concorrência em uma indústria tem raízes em sua estrutura econômica básica e vai além do comportamento dos atuais concorrentes.

Nesse sentido, para Porter (1980), a vantagem competitiva é resultado da capacidade da empresa de realizar eficientemente o conjunto de atividades necessárias para obter um custo mais baixo, que o dos concorrentes, ou de organizar essas atividades de uma forma única, capaz de gerar um valor diferenciado para os compradores. O papel reservado à estratégia é proteger a empresa da ação das forças competitivas.

O modelo ECP - Estrutura-Conduta-Performance, desenvolvido por Scherer e Ross (1990) e apresentado na figura 01, permite estabelecer a estratégia de negócios de uma empresa que busca atingir uma performance econômica superior. De acordo com o modelo ECP, a performance da empresa é o reflexo dos seus padrões de conduta ou práticas competitivas, que por sua vez, dependem da estrutura de mercado em que a empresa está inserida. O modelo está fundamentado no conceito de causalidade e parte da premissa que as empresas operam em uma estrutura de mercado aberto, onde os vendedores e os consumidores atuam em resposta aos sinais dos preços, gerados pela interferência da oferta e da demanda.

Figura 01 - Modelo Estrutura-Conduta-Performance -ECP (Copeland et al, 2000)

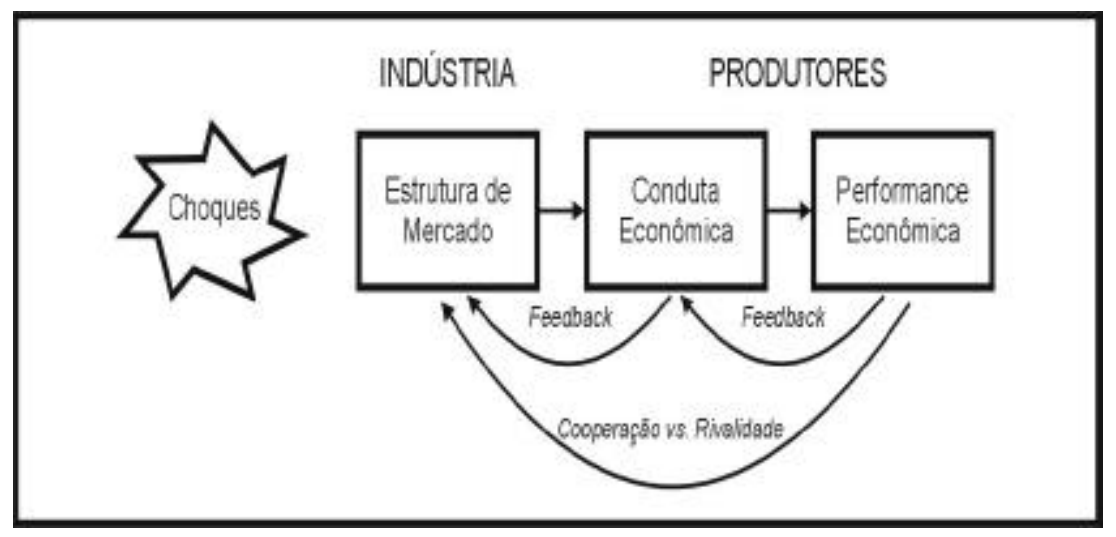

Segundo Copeland et al (2000), o modelo ECP acrescenta um elemento dinâmico à análise da estrutura da indústria. Esse modelo incorpora choques externos para analisar a sua influência na estrutura da indústria, na conduta dos participantes e, conseqüentemente, na performance destes. $\mathrm{Na}$ forma dinâmica, as mudanças ocorrem porque as empresas estão submetidas a eventos significativos que exigem respostas na conduta, com reflexos na performance e na própria estrutura de mercado. Esses eventos significativos, denominados de choques, são principalmente, oriundos de inovações tecnológicas, da ação governamental e de mudanças no comportamento social.

Analisando cada elemento do modelo ECP, observa-se que a estrutura é uma variável importante no ambiente competitivo, porque indica a capacidade que as empresas líderes têm de ordenar ou disciplinar o mercado. A estrutura de mercado é influenciada por uma variedade de condições básicas, 
oriundas da demanda e da oferta, e de políticas públicas, que incluem as regulamentações governamentais, como controle de preços e outras regras de comércio.

A conduta econômica é definida por Aguiar (1994), como o conjunto de atos, práticas e políticas utilizadas na coordenação das decisões da empresa sobre qual preço cobrar ou pagar, quanto vender ou comprar, que qualidade produzir ou comprar. $\mathrm{O}$ autor define, ainda, a performance como o grau de atendimento da sociedade pelo mercado, ou seja, é o nível de bemestar propiciado pelo mercado. Vasconcelos e Cyrino (2000) afirmam que a performance econômica da empresa é o resultado direto de seu comportamento concorrencial em termos de fixação de preços e custos e que esse comportamento depende da estrutura da indústria na qual as empresas estão inseridas.

Scherer (1996) alerta para uma falha de interpretação do modelo ECP a respeito do fluxo em uma única direção, ou seja, da estrutura de mercado para a conduta e em seguida para a performance. Na verdade, os efeitos dos feedbacks são igualmente significativos. Por exemplo, a definição do preço e o desenvolvimento de novos produtos podem ter um impacto na estrutura de mercado. Porter (1980) também reconhece a existência de feedbacks internos que conferem dinamismo ao modelo ECP.

Por outro lado, Ketola (1998) defende que, além dessas questões econômicas e políticas, as questões ambientais têm empurrado as empresas em direção ao planejamento ambiental estratégico. Dessa forma, as empresas tiram proveito das teorias de planejamento estratégico, para construir a visão ao nível corporativo, tendo a política ambiental como um elo entre a visão e o planejamento.

O modelo concebido por Elkington (1999) possibilita as empresas entrelaçarem os três componentes do desenvolvimento sustentável: prosperidade econômica, justiça social e proteção ao meio ambiente, dentro de suas operações principais e, essencialmente, fazendo o salto entre a sustentabilidade teórica para a prática. Dentro do contexto da agenda de sustentabilidade, a questão básica consiste em aproveitar os recursos do setor privado nestes novos imperativos sociais e econômicos, sem comprometer o meio ambiente e idealmente, aumentar os rendimentos econômicos e criar valor para a empresa.

Tomando por base a existência dessas três dimensões de performance, ou seja, ambiental e social, além da econômica, Abreu (2001) desenvolveu o Modelo ECP- Triplo - Estrutura-Conduta-PerformanceTriplo, apresentado na figura 02 . O modelo enfatiza a existência de um resultado final triplo, o qual eleva os resultados sociais e ambientais à mesma categoria dos econômicos.

Figura 02 - Modelo ECP-Triplo -Estrutura-Conduta-Performance Triplo (Abreu, 2001)

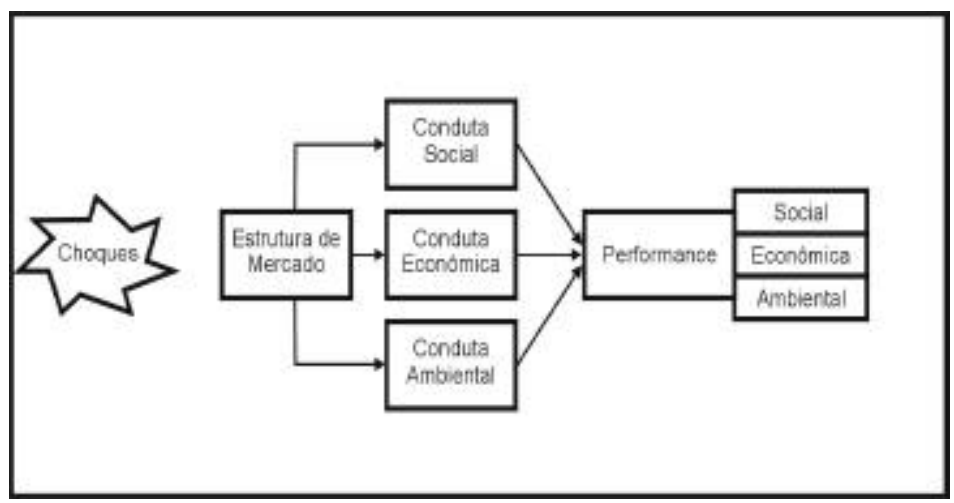


O modelo ECP-Triplo partiu da representação da indústria mostrada no modelo ECP - EstruturaConduta-Performance (Scherer e Ross, 1990). A dimensão ambiental é, então, detalhada no modelo de avaliação da estratégia ambiental, designado de modelo ECP-Ambiental. O desenvolvimento do modelo ECP-Ambiental preenche, portanto, essa lacuna deixada pelos modelos ambientais atuais, e possibilita projetar o desempenho ambiental futuro das empresas, contemplando a análise dinâmica da estrutura da indústria e da conduta ambiental dos participantes. O resultado dessa análise serve de subsídio ao processo de tomada de decisões gerenciais.

A concepção do modelo ECP-Ambiental, detalhado por Abreu (2001) e apresentado na figura 03, tem como princípio básico que as empresas atuam em um sistema de mercado aberto. O modelo permite inferir que a performance ambiental de uma empresa é o reflexo de suas práticas competitivas ou padrões de conduta ambiental, que por sua vez, dependem da estrutura de mercado em que está inserida. Na forma dinâmica, as mudanças ocorrem porque as empresas estão submetidas a eventos significativos, denominados choques, que exigem respostas na conduta ambiental, com reflexos na performance ambiental e na estrutura de mercado.

Figura 03 - Modelo Estrutura-Conduta-Performance Ambiental - ECP-Ambiental (Abreu, 2001)

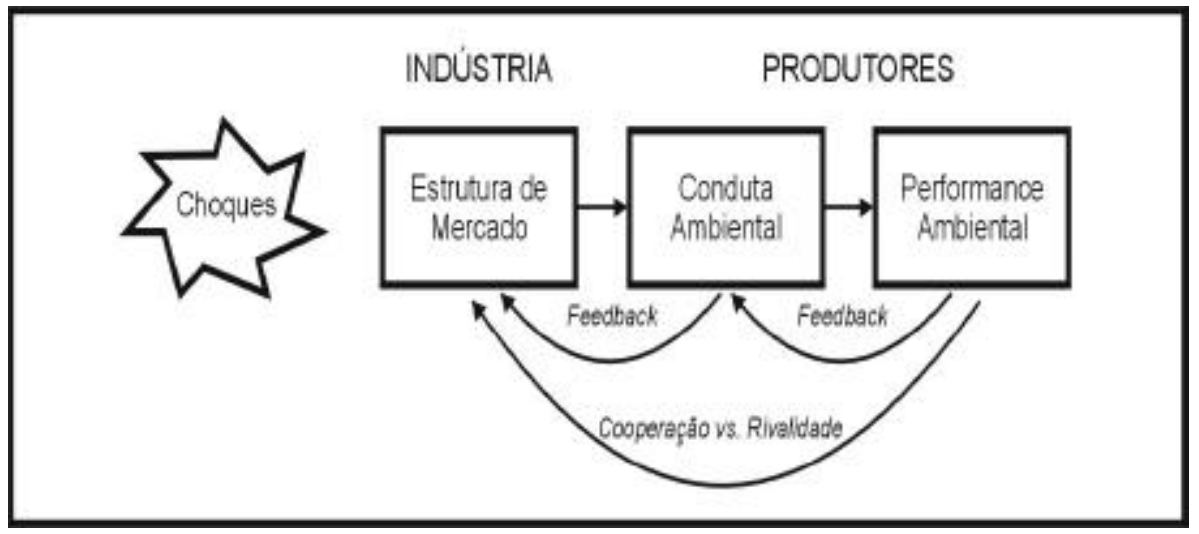

Os indicadores de estrutura de mercado, de conduta ambiental e de performance ambiental desenvolvidos no Modelo ECP-Ambiental são apresentados no quadro 01. Por definição, os indicadores da estrutura de mercado englobam os elementos de demanda e de oferta. Dessa forma, foram mantidos os indicadores de mercado definidos no modelo ECP (Scherer e Ross, 1990).

O conjunto de indicadores de conduta ambiental do modelo ECP-Ambiental foi desenvolvido buscando refletir a qualidade da gestão ambiental na empresa ao longo de seu sistema de negócios, envolvendo: pesquisa e desenvolvimento, compras, produção e manutenção, administração (geral, financeira, jurídica e de recursos humanos), marketing e distribuição. Na definição dos indicadores de conduta ambiental foram considerados os requisitos da ISO 14001 (1996), que estabelece as especificações e diretrizes para a implantação e uso do Sistema de Gestão Ambiental (SGA).

Abreu et al (2002) demonstraram que dependendo do posicionamento frente aos indicadores de conduta ambiental, as organizações podem ser classificadas em empresas com uma conduta ambiental forte, intermediária ou fraca, conforme a matriz apresentada no quadro 02. Usando o Modelo ECPAmbiental, os autores concluíram que as empresas com uma conduta ambiental forte fazem uma avaliação quantitativa da sua performance ambiental. Entretanto, as empresas com uma conduta 
ESTRATÉGIA - AS PRESSÕES AMBIENTAIS DA ESTRUTURA DA INDÚSTRIA

Mônica Cavalcanti Sá de Abreu - Gregório Jean VarvakisRados - Hugo Santana de Figueiredo Junior

ambiental intermediária estão iniciando o processo de quantificação da performance ambiental. Por outro lado, as empresas com uma conduta ambiental fraca não praticam essas medições.

Quadro 01 Indicadores do modelo ECP-Ambiental (Abreu, 2001)

\begin{tabular}{|c|c|c|c|}
\hline Choques & Estrutura de mercado & Conduta Ambiental & Performance Ambiental \\
\hline $\begin{array}{l}\text { Ação } \\
\text { Governamental } \\
\text { Política; } \\
\text { Legislação. }\end{array}$ & $\begin{array}{l}\text { Economia da demanda } \\
\text { Concentração de clientes; } \\
\text { Taxa de crescimento; } \\
\text { Volatilidade/ciclicidade; } \\
\text { Preferência dos clientes. } \\
\text { Economia da oferta } \\
\text { Concentração de produtores; } \\
\text { Disponibilidade de produtos } \\
\text { substitutos; } \\
\text { Diferenciação de produtos; } \\
\text { Competição } \\
\text { importadores/nacionais; } \\
\text { Estrutura de custo fixa/variável; } \\
\text { Utilização da capacidade } \\
\text { Oportunidades tecnológicas; } \\
\text { Forma da curva de oferta; } \\
\text { Barreiras de entrada/saída. }\end{array}$ & 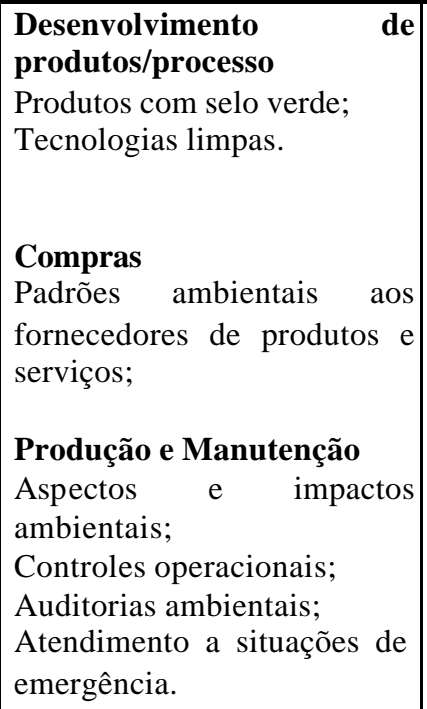 & 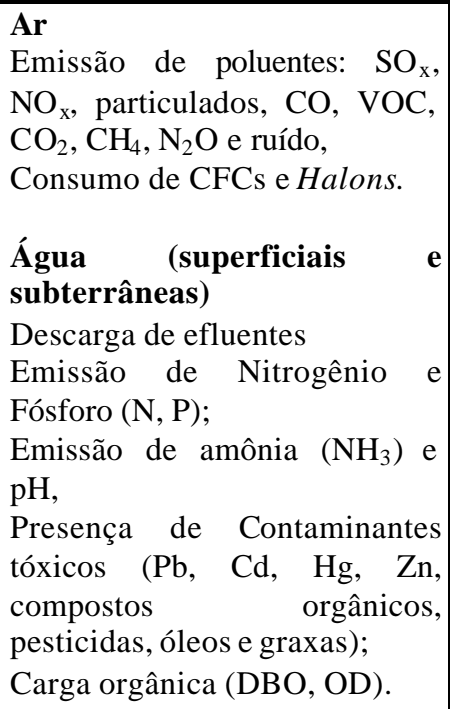 \\
\hline $\begin{array}{l}\text { Mudanças no } \\
\text { comportamento } \\
\text { social }\end{array}$ & $\begin{array}{l}\text { Economia da cadeia industrial } \\
\text { Poder de barganha dos } \\
\text { fornecedores; } \\
\text { Poder de barganha dos clientes; } \\
\text { Integração vertical do mercado; } \\
\text { Preço. } \\
\\
\text { Características Ambientais } \\
\text { Legislação ambiental; } \\
\text { Impacto ambiental; } \\
\text { Exigência ambientais das partes } \\
\text { interessadas. }\end{array}$ & $\begin{array}{l}\text { Administração } \\
\text { Geral } \\
\text { Política ambiental; } \\
\text { Estrutura organizacional; } \\
\text { Planejamento dos objetivos e } \\
\text { metas ambientais; } \\
\text { Documentação e controle de } \\
\text { documentos. } \\
\text { Financeira } \\
\text { Investimentos. } \\
\text { Jurídica } \\
\text { Legislação ambiental. } \\
\text { Recursos humanos } \\
\text { Programa de educação } \\
\text { ambiental. } \\
\text { Marketing } \\
\text { Comunicação com as partes } \\
\text { interessadas; } \\
\text { Imagem da empresa; } \\
\text { Exigências ambientais das } \\
\text { partes interessadas. } \\
\text { Distribuição } \\
\text { Canais de distribuição; } \\
\text { Transporte. }\end{array}$ & $\begin{array}{l}\text { Recursos Naturais } \\
\text { Uso dos recursos hídricos; } \\
\text { Uso dos recursos energéticos, } \\
\text { Uso dos recursos florestais; } \\
\text { Uso dos recursos marinhos. } \\
\text { Fauna \& Flora } \\
\text { Alteração do habitat; } \\
\text { Mudança no uso do solo; } \\
\text { Perda da biodiversidade. }\end{array}$ \\
\hline
\end{tabular}


Matriz de características de conduta ambiental

\begin{tabular}{|c|c|c|c|}
\hline \multirow[t]{2}{*}{ Funções Gerenciais } & \multicolumn{3}{|c|}{ Conduta ambiental } \\
\hline & Fraca & Intermediária & Forte \\
\hline Administração Geral & $\begin{array}{l}\text { Não existe gerência/departamento } \\
\text { ambiental na estrutura organizacional } \\
\text { com as atribuições definidas. } \\
\text { O nível gerencial é o mais alto para o } \\
\text { trato das questões ambientais. } \\
\text { Não assume compromissos formais em } \\
\text { uma política ambiental. } \\
\text { A importância da questão ambiental está } \\
\text { limitada ao atendimento dos } \\
\text { condicionantes da licença de operação. }\end{array}$ & $\begin{array}{l}\text { Existe um responsável dentro da } \\
\text { estrutura organizacional. } \\
\text { A diretoria é o nível mais alto para o } \\
\text { trato das questões ambientais. } \\
\text { Existem compromissos formais } \\
\text { estabelecidos na política ambiental. } \\
\text { A importância da questão não está } \\
\text { limitada ao atendimento à legislação } \\
\text { ambiental. } \\
\begin{array}{l}\text { Preocupadas com a imagem e em } \\
\text { alcançar novos mercados. }\end{array}\end{array}$ & $\begin{array}{l}\text { Existe uma gerência/departamento de } \\
\text { meio ambiente na estrutura } \\
\text { organizacional. } \\
\text { As questões ambientais são tratadas em } \\
\text { nível de presidência. } \\
\text { Existem compromissos formais em } \\
\text { atender à legislação, melhoria contínua } \\
\text { dos processos e prevenção da poluição. } \\
\text { A importância da questão está vinculada } \\
\text { ao compromisso com o desenvolvimento } \\
\text { sustentável. } \\
\text { Preocupados com a imagem da empresa }\end{array}$ \\
\hline $\begin{array}{l}\text { Administração } \\
\text { Jurídico }\end{array}$ & $\begin{array}{l}\text { Não } \\
\text { não } \\
\text { nanhece a legislação ambiental e } \\
\text { acompanhá-la. }\end{array}$ & $\begin{array}{l}\text { Conhece parcialmente a legislação } \\
\text { ambiental. } \\
\text { O acompanhamento do atendimento à } \\
\text { legislação é realizado de forma não } \\
\text { sistematizada pelo responsável pela área } \\
\text { de meio ambiente. }\end{array}$ & $\begin{array}{l}\text { Conhece integralmente a legislação. } \\
\text { Contrata consultoria externa para a sua } \\
\text { atualização. } \\
\text { O acompanhamento do atendimento à } \\
\text { legislação é realizado pela gerência de } \\
\text { meio ambiente e o jurídico. }\end{array}$ \\
\hline $\begin{array}{l}\text { Administração } \\
\text { Financeiro }\end{array}$ & $\begin{array}{l}\text { Os investimentos } \\
\text { representam de } \quad 0 \quad \text { ambientais } \\
\text { investimentos totais. } \\
\text { Definidos para atender à legislação } \\
\text { ambiental } \\
\text { Os ganhos financeiros estão atrelados às } \\
\text { vendas de resíduos e subprodutos sem } \\
\text { alteração do processo produtivo } \\
\text { Não consegue dimensionar esses ganhos. }\end{array}$ & $\begin{array}{l}\text { Os investimentos representam entre } 1 \text { a } \\
2 \% \text { dos investimentos totais. } \\
\text { Definidos com base nos projetos gerados } \\
\text { internamente de forma espontânea. } \\
\text { Os ganhos financeiros estão atrelados a } \\
\text { redução do desperdício, relacionada aos } \\
\text { insumos água e energia elétrica, e a } \\
\text { comercialização dos resíduos. }\end{array}$ & $\begin{array}{l}\text { Os investimentos representam mais de } \\
2 \% \text { dos investimentos totais da empresa. } \\
\text { Definidos com base nos objetivos e } \\
\text { metas ambientais. } \\
\text { Os ganhos financeiros estão atrelados à } \\
\text { redução das perdas de processo, } \\
\text { Podem existir investimentos ambientais } \\
\text { sem retorno financeiro. }\end{array}$ \\
\hline
\end{tabular}




\begin{tabular}{|c|c|c|c|}
\hline \multicolumn{4}{|c|}{ Matriz de características de conduta ambiental } \\
\hline \multirow[t]{2}{*}{ Funções Ge renciais } & \multicolumn{3}{|c|}{ Conduta ambiental } \\
\hline & Fraca & Intermediária & Forte \\
\hline $\begin{array}{l}\text { Administração } \\
\text { Recursos Humanos }\end{array}$ & $\begin{array}{l}\text { Não existe um programa de educação } \\
\text { ambiental. }\end{array}$ & $\begin{array}{l}\text { Possui um programa de educação } \\
\text { ambiental voltado para ações básicas } \\
\text { como a coleta seletiva de lixo, e } \\
\text { desenvolvido informamente através de } \\
\text { palestras. } \\
\text { Frequiência anual. }\end{array}$ & $\begin{array}{l}\text { Possui um programa de educação } \\
\text { ambiental voltado para os funcionários e } \\
\text { para a comunidade. Diariamente são } \\
\text { realizados diálogos envolvendo aspectos } \\
\text { ambientais nas atividades de produção. } \\
\text { Realiza eventos anualmente como a } \\
\text { semana de meio ambiente e treinamento } \\
\text { de integração para os novos } \\
\text { funcionários. }\end{array}$ \\
\hline $\begin{array}{l}\text { Produção } \\
\text { Manutenção }\end{array}$ & $\begin{array}{l}\text { Não possui um sistema de gestão } \\
\text { ambiental. } \\
\text { Não avalia os impactos ambientais de } \\
\text { suas atividades, produtos e serviços. } \\
\text { Não realiza auditorias ambientais. } \\
\text { Os controles operacionais atrelados aos } \\
\text { insumos da produção. } \\
\text { Não adota uma sistemática de melhoria } \\
\text { contínua para os indicadores de } \\
\text { performance. }\end{array}$ & $\begin{array}{l}\text { Está em processo de implementação de } \\
\text { um sistema de gestão ambiental. } \\
\text { Avalia os impactos ambientais de suas } \\
\text { atividades, produtos e serviços. } \\
\text { Processo imaturo de auditorias } \\
\text { ambientais semestrais. } \\
\text { Controles operacionais atrelados aos } \\
\text { insumos de processo e o atendimento da } \\
\text { legislação ambiental. } \\
\text { Os indicadores ambientais foram } \\
\text { estabelecidos através dos pa drões legais. } \\
\text { Não existe uma sistemática de melhoria } \\
\text { contínua dos indicadores de } \\
\text { performance, apenas conformidade } \\
\text { legal. }\end{array}$ & $\begin{array}{l}\text { Possui um sistema de gestão ambiental } \\
\text { certificado pela ISO } 14001 \text {. } \\
\text { Faz o levantamento e avaliação dos } \\
\text { aspectos e impactos ambientais de suas } \\
\text { atividades, produtos e serviços. } \\
\text { Realiza auditorias ambientais internas. } \\
\text { Os indicadores ambientais foram } \\
\text { estabelecidos com base nos padrões } \\
\text { legais e em comparação com outras } \\
\text { unidades da empresa ou histórico de } \\
\text { desempenho. } \\
\text { Adota uma sistemática de melhoria } \\
\text { contínua dos indicadores ambientais. }\end{array}$ \\
\hline $\begin{array}{l}\text { Desenvolvimento de } \\
\text { produtos \& processo }\end{array}$ & $\begin{array}{l}\text { Não adota tecnologias para minimizar o } \\
\text { impacto ambiental. }\end{array}$ & $\begin{array}{l}\text { Investe na aquisição de equipamentos } \\
\text { com um menor consumo de insumos. }\end{array}$ & $\begin{array}{l}\text { Desenvolve tecnologias para minimizar } \\
\text { o impacto ambiental de seus processos } \\
\text { produtivos. } \\
\text { Produtos certificados com o selo verde }\end{array}$ \\
\hline
\end{tabular}




\begin{tabular}{|c|c|c|c|}
\hline \multicolumn{4}{|c|}{ Matriz de características de conduta ambiental } \\
\hline \multirow[t]{2}{*}{ Funções Gerenciais } & \multicolumn{3}{|c|}{ Conduta ambiental } \\
\hline & Fraco & Intermediária & Forte \\
\hline Marketing & $\begin{array}{l}\text { Não possui uma sistemática para tratar } \\
\text { as reclamações ambientais das partes } \\
\text { interessadas. } \\
\text { Não produz relatório de performance } \\
\text { ambiental. } \\
\text { Desconhece a preocupação ambiental } \\
\text { por parte dos concorrentes; } \\
\text { Não identifica vantagens competitivas } \\
\text { com a performance ambiental. }\end{array}$ & $\begin{array}{l}\text { Utiliza a sistemática de aendimento ao } \\
\text { cliente para tratamento das reclamações } \\
\text { das partes interessadas. } \\
\text { Não produz relatórios de performance } \\
\text { ambiental. } \\
\text { Percebe a preocupação ambiental de } \\
\text { seus concorrentes. } \\
\text { Está começando a identificar algumas } \\
\text { vantagens competitivas com a questão } \\
\text { ambiental. }\end{array}$ & $\begin{array}{l}\text { Desenvolveu uma sistemática para } \\
\text { atendimento, acompanhamento } \\
\text { registro das reclamações ambientais das } \\
\text { partes interessadas. } \\
\text { Desenvolve relatórios ambientais } \\
\text { disponíveis ao público. } \\
\text { Antecipa as preocupações ambientais de } \\
\text { seus clientes. } \\
\text { Alcança uma vantagem competitiva } \\
\text { através de uma atuação ambientalmente } \\
\text { consciente e pró-ativa. }\end{array}$ \\
\hline Compras & $\begin{array}{l}\text { Não adota padrões ambientais aos } \\
\text { fornecedores de bens e serviços. }\end{array}$ & $\begin{array}{l}\text { Adota parcialmente padrões ambientais } \\
\text { aos seus fornecedores de serviços. }\end{array}$ & $\begin{array}{l}\text { Adota padrões ambientais para a } \\
\text { qualificação de todos os seus } \\
\text { fornecedores de bens e serviços }\end{array}$ \\
\hline Distribuição & $\begin{array}{l}\text { Não identifica os riscos ambientais na } \\
\text { distribuição de seus produtos. }\end{array}$ & $\begin{array}{l}\text { Identifica riscos de acidentes na } \\
\text { distribuiçãa de seus produtos } \\
\text { Adota alguns critérios para a distribuição } \\
\text { de produtos. }\end{array}$ & $\begin{array}{l}\text { Adota critérios rigorosos de prevenção } \\
\text { da poluiçãa para distribuição dos seus } \\
\text { produtos. } \\
\text { Adota medidas preventivas para evitar } \\
\text { acidentes. }\end{array}$ \\
\hline
\end{tabular}


Segundo Murray et al (1996), os indicadores de performance ambiental são ditados por meio das preocupações sociais, das percepções públicas, dos desejos e das necessidades das partes interessadas. Dessa forma, o conjunto de indicadores de performance ambiental do modelo ECPAmbiental foi construído a partir do modelo Pressão-Estado-Resposta - PSR (OECD, 1998), que considera as prioridades dos países em termos de performance ambiental, visando uma melhor integração entre as preocupações ambientais com as tomadas de decisões entre as nações. Essas prioridades se refletem em ações individuais ou coletivas para mitigar, adaptar ou prevenir os impactos ambientais, além de conservar os recursos naturais. Todavia, um número maior de indicadores ambientais para entender e descrever a performance ambiental, em virtude do meio ambiente conter um número de compartimentos representados pelo ar, água, solo, recursos naturais, fauna e flora, largamente dependentes um do outro em termos de medição e controle das descargas.

\section{A PESQUISA PARA APLICAÇÃO DO MODELO ECP-AMBIENTAL}

A aplicação do Modelo ECP-Ambiental ocorreu através da coleta de dados primários e da condução de entrevistas diretas em setores industriais que permitissem a comparação entre as empresas, em função do seu produto final. $\mathrm{O}$ delineamento da pesquisa tomou como base os critérios: a estrutura de mercado e o impacto ambiental. Com relação ao impacto ambiental, foram definidos setores industriais que resultassem em baixo, intermediário e elevado impacto ambiental.

Os setores petroquímico, têxtil e de bebidas foram selecionados. O critério da paridade foi utilizado na definição da amostra a ser pesquisada, ou seja, a amostra sistemática contém pelo menos duas empresas para cada produto final, de modo a permitir a comparação entre empresas competidoras. A amostra selecionada foi estratificada em empresas produtoras de petroquímicos básicos e finais; de produtos têxteis de algodão - fios, tecidos planos e malhas; e de bebidas - refrigerantes e água mineral.

A pesquisa obteve o apoio do SENAI e as entrevistas foram conduzidas nos estados do Ceará, de Pernambuco, da Bahia, de Santa Catarina e do Rio Grande do Sul, durante cinco meses, conforme apresentado no quadro 03. O contato com as empresas teve início com o envio de uma correspondência do SENAI, explicando os objetivos da pesquisa e anexando o questionário desenvolvido por Abreu (2001), que avalia o comportamento dos indicadores de estrutura de mercado, de conduta e de performance ambiental. Em seguida, agendava-se a entrevista com um dirigente da empresa credenciado para fornecer informações precisas.

Quadro 03 Tamanho da amostra pesquisada por estado e por setor industrial (Abreu, 2001).

\begin{tabular}{|c|c|c|c|c|c|c|c|}
\hline \multirow[t]{3}{*}{ Estados } & \multicolumn{7}{|c|}{ Setores Industriais } \\
\hline & \multicolumn{2}{|c|}{ Petroquímico } & \multicolumn{3}{|c|}{ Têxtil } & \multicolumn{2}{|c|}{ Bebidas } \\
\hline & Básicos & Finais & Fiação & $\begin{array}{c}\text { Tecelagem } \\
\text { Plana }\end{array}$ & Malharia & Água & Refrigerantes \\
\hline $\begin{array}{l}\text { Ceará } \\
\text { Bahia } \\
\text { Pernambuco } \\
\text { Rio Grande do Sul } \\
\text { Santa Catarina }\end{array}$ & $\begin{array}{l}1 \\
1\end{array}$ & $\begin{array}{l}2 \\
3\end{array}$ & 2 & 3 & 2 & 3 & $\begin{array}{l}1 \\
1\end{array}$ \\
\hline \multirow[t]{2}{*}{ TOTAL (N) } & 2 & 5 & 2 & 3 & 3 & 3 & 2 \\
\hline & \multicolumn{2}{|l|}{7} & \multicolumn{3}{|l|}{8} & \multicolumn{2}{|l|}{5} \\
\hline
\end{tabular}


O setor petroquímico, no Brasil, possui uma concentração de empresas instaladas nos pólos petroquímicos de São Paulo, Camaçari e Triunfo, localizados em São Paulo, Bahia e Rio Grande do Sul, respectivamente. No setor petroquímico foram pesquisadas sete empresas, sendo quatro instaladas no pólo de Triunfo e três empresas no pólo de Camaçari. As empresas petroquímicas entrevistadas são as centrais de matérias-primas dos pólos e as empresas produtoras de resinas poliméricas.

O impacto ambiental da indústria petroquímica ocorre em todos os compartimentos ambientais, envolvendo a fauna e a flora, a água, o ar, o solo e os recursos naturais. O processo petroquímico opera com elevado impacto ambiental, com riscos de incêndios, explosões e vazamentos, o que exige elevados investimentos em controles operacionais.

O setor têxtil possui certa concentração regional de produção, estando as empresas instaladas principalmente nos estados de São Paulo, Santa Catarina, Ceará, Minas Gerais, Pernambuco e Rio de Janeiro. Os dados foram levantados em oito empresas, sendo sete instaladas no Ceará e uma em Santa Catarina. A quase totalidade das entrevistas desenvolveu-se no Ceará, em virtude do acesso às informações. $\mathrm{O}$ impacto ambiental das atividades têxteis está relacionado ao elevado consumo de energia elétrica, de água e o lançamento de contaminantes nos corpos receptores.

O setor de bebidas está distribuído em todo o país, a pesquisa aconteceu em cinco empresas, sendo quatro instaladas no Ceará e uma em Pernambuco. A entrevista em Pernambuco ocorreu em uma empresa de refrigerantes, vulgarmente denominados de tubaína, com o objetivo de entender o papel dos novos competidores, como um elemento dinâmico do modelo ECP-Ambiental. O fornecimento de água é um dos principais elementos para a construção de uma fábrica de refrigerantes e de água mineral. O impacto ambiental do setor de bebidas está, portanto, relacionado com a quantidade de água consumida e de efluente hídrico gerado em elevadas vazões e com alta carga orgânica.

\section{AS PRESSÕES AMBIENTAIS DA ESTRUTURA DA INDÚSTRIA}

\section{A Pressão da Legislação Ambiental}

As sanções administrativas impostas pelos órgãos estaduais de meio ambiente às empresas entrevistadas são apresentadas na tabela 01. A análise do número de multas sofridas pelas empresas sinaliza a atuação dos órgãos de fiscalização ambiental nos estados em que a pesquisa foi realizada. O número de multas permite também, analisar a performance das empresas, como um reflexo de condutas ambientais específicas.

Tabela 01 Sanções administrativas ambientais impostas às empresas entrevistadas (Abreu, 2001)

\begin{tabular}{|l|l|l|l|l|}
\hline Indicadores & Respostas & \multicolumn{3}{|l|}{ Número de empresas do setor } \\
\cline { 3 - 5 } & & Petroquímico & Têxtil & Bebidas \\
\hline $\begin{array}{l}\text { Número de Sanções } \\
\text { Administrativas }\end{array}$ & Multas & 5 & - & 1 \\
Ambientais & Notificações & - & 3 & 2 \\
& $\begin{array}{l}\text { Nunca foi multado ou } \\
\text { autuado }\end{array}$ & 2 & 5 & 2 \\
\hline
\end{tabular}

A pesquisa revela que nos estados onde os pólos petroquímicos estão instalados, cinco empresas já foram multadas e, somente duas não sofreram sanções administrativas ambientais. Por outro lado, cinco empresas têxteis entrevistadas nunca foram multadas e apenas três foram notificadas. Para as 
empresas de bebidas, observa-se que apenas uma das empresas, instalada em Pernambuco, foi multada e duas receberam notificações relacionadas com atraso nas obras da estação de tratamento de efluentes, decorrentes de denúncias da comunidade. O restante, ou seja, duas das empresas de bebidas nunca foram multadas.

A distribuição de frequiência para a função gerencial administração jurídica, apresentada na tabela 02, revela o conhecimento da legislação ambiental, aplicável aos aspectos ambientais de suas atividades, produtos e serviços das empresas. Dentro do universo pesquisado, seis empresas petroquímicas conhecem e acompanham a atualização dessa legislação. Em virtude da complexidade desse trabalho e da carência de recursos humanos internos, essas empresas contratam consultorias externas. O conhecimento parcial da legislação acontece em apenas uma das empresas entrevistadas.

Tabela 02 Conduta ambiental para a função gerencial administração jurídica. (Abreu, 2001).

\begin{tabular}{|l|l|l|l|l|}
\hline Indicadores & Respostas & \multicolumn{4}{|l|}{ Número de empresas do setor } \\
\cline { 3 - 5 } & & Petroquímico & Têxtil & Bebidas \\
\hline $\begin{array}{l}\text { Conhecimento da } \\
\text { legislação ambiental }\end{array}$ & Sim & 6 & 1 & - \\
aplicável & Sim, parcialmente & 1 & 2 & 1 \\
& Não & & 5 & 4 \\
\hline
\end{tabular}

Por outro lado, as empresas têxteis, em sua grande maioria, não conhecem a legislação ambiental. Cinco empresas revelaram o desconhecimento desta legislação. O conhecimento parcial da legislação acontece em duas empresas entrevistadas e apenas uma afirma conhecer e acompanhar toda a legislação ambiental. Comportamento similar acontecesse com as empresas de bebidas, onde quatro empresas não conhecem e não acompanham a legislação ambiental. O conhecimento parcial da legislação ambie ntal está restrito a uma única empresa entrevistada.

O artigo "Natureza paga o preço da discórdia no setor" (Brasil Energia, maio, 2001) relata que o Brasil possui uma regulamentação diversificada e espalhada por diversos órgãos ambientais estaduais, além de um sistema de precário de fiscalização. Em meio a desordem e a falta de preparo em relação a regulamentação e a fiscalização do meio ambiente, o Rio Grande do Sul - onde está instalado o pólo de Triunfo - se destaca como sendo um dos mais cuidadosos do país. A Fundação Estadual de Proteção Ambiental (FEPAM), implementa uma série de iniciativas, que abrangem desde de relatórios mensais obrigatórios até vistorias de rotina a cada três meses. Este comportamento da FEPAM, em parte, pode justificar o maior percentual de multas ao setor petroquímico obtido na pesquisa.

Porter (1999) assinala que a regulamentação ambiental deve ser severa. A legislação branda, ao contrário, faz com que as empresas busquem soluções improvisadas ou secundárias. Assim, a regulamentação deve ser bastante rigorosa para promover uma efetiva inovação tecnológica. $\mathrm{O}$ autor afirma que a imposição de padrões ambientais adequados pode estimular as empresas a adotarem inovações que reduzem os custos totais de um produto e aumentem seu valor, melhorando a competitividade das empresas.

Nesse sentido, os resultados comprovam que a legislação ambiental constitui uma característica importante da estrutura da indústria. Quando a regulamentação é rígida e a fiscalização atuante, exerce uma alta pressão da estrutura da indústria e induz às empresas a adotarem soluções para as questões ambientais. Por outro lado, quando a regulamentação e a fiscalização são incipientes, essa característica exerce uma fraca pressão da estrutura da indústria. 


\section{A Pressão dos Impactos Ambientais}

A pesquisa revelou cinco empresas petroquímicas certificadas pela ISO 14001. Essas empresas fazem uma avaliação continuada dos seus aspectos e impactos ambientais, e periodicamente passam por auditorias ambientais. O restante das empresas petroquímicas pesquisadas implantaram os rígidos códigos de prática do Atuação Responsável, que consiste de um modelo de gestão nas áreas de meio ambiente, saúde e segurança no trabalho, obrigatórios para as indústrias químicas (ABIQUIM, 2001), e utilizaram os resultados do EIA/RIMA para a avaliação dos seus impactos ambientais. Nestas empresas o processo de auditorias ambientais não estava sistematizado.

No setor têxtil, foi entrevistada uma empresa certificada pela ISO 14001, duas que estavam em processo final de certificação, três que tinham planos de implantar o SGA e duas que não tinham planos de implantar o SGA. Como consequiência da implantação da ISO 14001, as três empresas realizaram uma avaliação continuada dos aspectos e impactos ambientais e passaram por auditorias ambientais.

A pesquisa revelou também que uma das empresas de bebidas possui Sistema de Gestão Ambiental, definido pela Matriz Americana, e faz a avaliação dos impactos ambientais. Para o restante das empresas, a implantação de um SGA não está nos planos e, portanto, não avaliam os seus impactos ambientais.

Durante a pesquisa, as empresas foram questionadas sobre os principais impactos ambientais decorrentes dos seus processos produtivos. As respostas estão apresentadas na tabela 03, cabendo ressaltar que a soma dos percentuais ultrapassa $100 \%$ porque a empresa poderia assinalar mais de um impacto ambiental. As empresas petroquímicas admitem que os seus principais impactos ambientais estão relacionados com a qualidade do efluente hídrico, seguida da geração de resíduos sólidos e do ruído emitido por suas instalações. A pesquisa revelou uma preocupação com a qualidade do ar, oriundo da emissão de VOC, e com a mudança climática, decorrente da emissão de dióxido de carbono e da destruição da camada de ozônio.

Tabela 03 Distribuição de freqüências dos principais impactos ambientais oriundos do processo industrial na visão dos setores pesquisados (Abreu, 2001)

\begin{tabular}{|l|l|l|l|}
\hline \multirow{2}{*}{ Impactos Ambientais } & \multicolumn{3}{|l|}{ Número de empresas do setor } \\
\cline { 2 - 4 } & Petroquímico & Têxtil & Bebidas \\
\hline Mudança climática & 2 & 2 & 0 \\
Destruição da camada de ozônio & 2 & 0 & 0 \\
Qualidade do ar & 3 & 1 & 0 \\
Ruído & 4 & 5 & 3 \\
Geração de resíduos sólidos & 4 & 1 & 1 \\
perigosos do efluente hídrico & 6 & & \\
Qualidade dón & 7 & 3 \\
Exaustão dos recursos hídricos & 2 & 2 & 2 \\
Exaustão dos recursos naturais & 2 & 2 & 2 \\
Energia & 2 & 7 & 2 \\
\hline
\end{tabular}

Por outro lado, as empresas têxteis admitem que o lançamento de efluente hídrico no corpo receptor e o consumo de energia elétrica são os principais impactos ambientais decorrentes da sua atividade produtiva. Cinco empresas têxteis estão preocupadas com o ruído emitido por suas instalações, em virtude das reclamações das comunidades vizinhas à unidade fabril e da possibilidade de fiscalização pelo órgão governamental. Em menor escala, as empresas admitem o impacto da 
exaustão dos recursos naturais e da mudança climática. Somente uma empresa amplia suas preocupações para os resíduos perigosos gerados.

As empresas de bebidas, por sua vez, admitem o impacto ambiental da exaustão dos recursos hídricos, decorrente do elevado consumo de água no processo produtivo. Em seguida, três empresas afirmaram que o ruído e a qualidade do efluente hídrico, lançado no corpo receptor, representam impactos ambientais significativos. Somente uma empresa, do universo pesquisado, percebe que os resíduos gerados associam uma imagem negativa a empresa, como poluidora de praias.

A pesquisa levantou, também, os principais controles operacionais implantados nas empresas para mitigar e prevenir os impactos ambientais. Observa-se na tabela 04, que todas as empresas petroquímicas definiram, prioritariamente, controles para os efluentes líquidos e os resíduos sólidos, seguido do consumo de água, de energia elétrica e de energéticos. O ruído também está sendo controlado em quatro empresas. Finalmente, as emissões fugitivas de hidrocarbonetos são controladas em apenas duas das empresas pesquisadas.

Para as empresas têxteis, observa-se a definição de controles operacionais para a água e energia elétrica, como consequiência da escassez dos recursos, do elevado consumo, e do impacto desses insumos no desempenho econômico das empresas. Considerando também, o cenário de crise de energia elétrica, que atuou como um choque, esse insumo passou a ser controlado, através das políticas de governo que obrigavam a redução do consumo. O ruído é uma outra preocupação para cinco empresas, em virtude de terem sofrido alguma reclamação da comunidade vizinha ou estão sujeitos a problemas de perda auditiva em seus funcionários. Foi verificado que, apenas quatro empresas estabeleceram controles operacionais para adequar seus efluentes líquidos aos padrões legais, partindo de reclamações da comunidade ou fiscalização ambiental, comportamento semelhante foi observado para os resíduos sólidos. Os energéticos são controlados em apenas duas das empresas entrevistadas.

Tabela 04 Principais controles operacionais implantados para prevenir ou mitigar os impactos ambientais. (Abreu, 2001)

\begin{tabular}{|c|c|c|c|c|}
\hline \multirow[t]{2}{*}{ Indicadores } & \multirow[t]{2}{*}{ Respostas } & \multicolumn{3}{|c|}{$\begin{array}{l}\text { Número de empresas do } \\
\text { Setor }\end{array}$} \\
\hline & & Petroquímico & Têxtil & Bebidas \\
\hline Controles operacionais & $\begin{array}{l}\text { Tratamento dos Efluentes líquidos } \\
\text { Gerenciamento dos resíduos perigosos } \\
\text { Coleta Seletiva } \\
\text { Conservação da Água } \\
\text { Monitoramento das Emissões atmosféricas das } \\
\text { fontes fixas } \\
\text { Monitoramento das Emissões atmosféricas das } \\
\text { fontes móveis } \\
\text { Monitoramento das Emissões fugitivas } \\
\text { Conservação de Energia elétrica } \\
\text { Conservação de Energéticos (vapor, ar } \\
\text { comprimido, óleo combustível, gás natural) } \\
\text { Controle do Ruído }\end{array}$ & $\begin{array}{l}7 \\
7 \\
6 \\
5\end{array}$ & \begin{tabular}{|l}
4 \\
4 \\
8 \\
3
\end{tabular} & $\begin{array}{l}4 \\
3 \\
4 \\
1 \\
1\end{array}$ \\
\hline
\end{tabular}

A escassez de água e de energia elétrica também obriga as empresas de bebidas a controlarem esses insumos do processo. Decorrente da obrigação legal, quatro empresas estabeleceram controles para os efluentes líquidos. Por outro lado, considerando que parte dos resíduos pode ser reciclada, três empresas implantaram a coleta seletiva, entretanto, nenhum controle foi implantado para os resíduos perigosos. 
Esses resultados mostram uma maior diversidade de impactos ambientais para o setor petroquímico. Os impactos ambientais demandam, portanto, das empresas petroquímicas um controle operacional rigoroso e exercem uma alta pressão da estrutura da indústria. O setor têxtil pode ser caracterizado com um impacto ambiental intermediário, o que implica que a pressão da estrutura da indústria depende de como está internalizada a variável ambiental na empresa. Por outro lado, os resultados com as empresas de bebidas comprovam que o baixo impacto ambiental do processo produtivo exerce uma baixa pressão da estrutura da indústria, comprovada através da definição de poucos controles operacionais.

\section{A Pressão das Exigências Ambientais das Partes Interessadas}

As entrevistas as empresas petroquímicas, têxteis e de bebidas revelaram as exigências ambientais dos seus clientes, conforme apresentadas na tabela 05 . Duas empresas petroquímicas afirmaram que os clientes exigem o certificado ISO 14001, em outra empresa, os clientes desenvolveram normas próprias contemplando os padrões ambientais a serem seguidos e auditados, no restante das empresas, seus clientes não possuem exigências ambientais. As empresas têxteis, por sua vez, têm metade dos clientes com exigências ambientais definidos por padrões próprios. Do lado oposto, os clientes das empresas de bebidas não fazem nenhum tipo de exigência ambiental.

Tabela 05 Exigências ambientais dos clientes (Abreu, 2001)

\begin{tabular}{|l|l|l|l|l|}
\hline Indicadores & Respostas & \multicolumn{3}{|l|}{ Número de empresas do Setor } \\
\cline { 3 - 5 } & & Petroquímico & Têxtil & Bebidas \\
\hline Exigências & Selo verde & - & - & - \\
ambientais dos & ISO 14001 & 2 & - & - \\
clientes & Norma dos próprios clientes & 1 & 4 & - \\
& Não têm exigências ambientais & 4 & 4 & 5 \\
\hline
\end{tabular}

Dentro da ótica das partes interessadas, a tabela 06 mostra que os acionistas, prioritariamente, influenciam na estratégia ambiental da empresa, em seguida, estão os órgãos governamentais. Estes resultados confirmam a influência da fiscalização ambiental como parte integrante da característica ambiental da estrutura de mercado, definida no modelo ECP-Ambiental. Excluindo, então, a influência dos acionistas e do governo observa-se que em cinco empresas petroquímicas tanto a comunidade como os clientes do mercado interno exercem uma influência marcante na definição da estratégia. Em menor percentual, mas ainda exercendo influência na estratégia, estão os clientes do mercado externo.

Os resultados com a comunidade e os clientes se repetem no setor têxtil, entretanto, com uma influência discreta na estratégia ambiental das empresas. Observa-se que, em quatro empresas têxteis entrevistadas os clientes do mercado externo influenciam na estratégia. Em menor escala, estão a comunidade e os clientes do mercado interno. Da mesma frma, a comunidade exerce influência em duas empresas de bebidas que fizeram parte da pesquisa. 
Tabela 06 Partes interessadas que influenciam na definição da estratégia ambiental da empresa (Abreu, 2001)

\begin{tabular}{|l|l|l|l|l|}
\hline Indicadores & Respostas & \multicolumn{3}{|l|}{ Setores Industriais } \\
\cline { 3 - 5 } & & Petroquímico & Têxtil & Bebidas \\
\hline Partes & Acionistas & 6 & 7 & 4 \\
interessadas que & Órgãos Governamentais & 5 & 7 & 4 \\
influenciam nam & Comunidade & 5 & 3 & 2 \\
estratégia & Clientes do mercado interno & 5 & 3 & - \\
ambiental da & Clientes do mercado externo & 4 & 4 & - \\
empresa & Agentes financiadores & 2 & 1 & - \\
& Funcionários & 2 & 1 & - \\
& Organizações Não-Governamentais & 1 & 1 & - \\
\hline
\end{tabular}

Estes resultados mostram que a comunidade vizinha à empresa, em virtude de sofrer diretamente os impactos ambientais das atividades, produtos e serviços da empresa está interessada na performance da empresa. Nesse sentido, Whitaker (1999) argumenta também, que grandes corporações permanecem dependentes de uma "licença social para operar o negócio", a qual pode ser sumariamente revogada caso sejam percebidas transgressões ambientais.

Analisando a influência dos agentes financiadores e os funcionários, verifica-se que nas empresas petroquímicas e têxteis exercem influência restrita, seguida das organizações não-governamentais. Por outro lado, os agentes financiadores, os funcionários e as organizações não-governamentais não são considerados na definição da estratégia ambiental das empresas de bebidas.

Quando os resultados obtidos para o modelo ECP-Ambiental são comparados com o modelo proposto por Elkington (1999) observa-se que as exigências ambientais das principais partes interessadas - clientes e comunidade - estão relacionadas com a primeira e a segunda revolução, respectivamente. A primeira revolução dita que as empresas passaram a competir em mercados mais abertos e altamente competitivos, crescendo o número de empresas que sofrem mudanças ditadas por seus clientes e por mercados financeiros, exigindo comprometimentos e performances econômicas, sociais e ambientais.

A segunda revolução está sendo dirigida pelas mudanças nos valores humanos e sociais. A inserção dos valores ambientais e sociais leva a grande maioria das empresas e a sociedade a terem preocupações do tipo: quais os impactos ambientais e os riscos à saúde e à segurança no trabalho de um produto ou um processo?

De acordo com Rodriguez e Ricart (1998), as partes interessadas mais importantes, tanto do ponto de vista ambiental ou puramente competitivo, são os clientes. Com base no exposto, conclui-se que, quando as exigências ambientais das partes interessadas são efetivas, elas interferem nas decisões estratégicas das empresas e podem ser considerados elementos essenciais na busca da sustentabilidade. 


\section{A Matriz de Correlação entre a Pressão da Estrutura da Indústria e a Conduta Ambiental.}

A combinação dessas fontes individuais de pressão ambiental vai determinar se a pressão da estrutura da indústria é alta ou baixa, conforme apresentado no quadro 04. Os resultados obtidos indicam que a indústria petroquímica sofre altas pressões ambientais, em virtude do alto impacto ambiental inerente as suas atividades, produtos e serviços, da regulamentação rígida e da fiscalização atuante, nos estados onde os pólos estão instalados, das influências exercidas por clientes e a comunidade nos seus controles operacionais. Por outro lado, as indústrias têxteis e de bebidas estão sujeitas a baixas pressões, decorrentes de um baixo impacto ambiental, de uma regulamentação e fiscalização incipientes, e seus clientes não manifestaram exigências ambientais.

Quadro 04 Pressões ambientais da estrutura da indústria (Abreu, 2001)

\begin{tabular}{|l|l|l|}
\hline $\begin{array}{l}\text { Características da Estrutura da } \\
\text { Indústria }\end{array}$ & Pressão \\
\cline { 2 - 3 } & Alta & Baixa \\
\hline $\begin{array}{l}\text { Impacto Ambiental inerente ao } \\
\text { processo produtivo e variável com } \\
\text { a escala de produção e a tecnologia } \\
\text { adotada }\end{array}$ & $\begin{array}{l}\text { Alto impacto ambiental } \\
\text { das atividades, produtos ou } \\
\text { serviços }\end{array}$ & $\begin{array}{l}\text { Baixo impacto ambiental } \\
\text { das atividades, produtos } \\
\text { ou serviços }\end{array}$ \\
\hline Legislação Ambiental & $\begin{array}{l}\text { Regulamentação rígida e e } \\
\text { fiscalização atuante }\end{array}$ & $\begin{array}{l}\text { Regulamentação } \\
\text { fiscalização incipientes }\end{array}$ \\
\hline $\begin{array}{l}\text { Exigências Ambientais das Partes } \\
\text { Interessadas }\end{array}$ & Exigências reais & Exigências potenciais \\
\hline
\end{tabular}

A definição de perfis de conduta ambiental e o entendimento das pressões da estrutura das indústrias permitem construir uma matriz de correlação. Esta matriz, apresentada na figura 04, mostra seis tipos de posicionamentos estratégicos que dependem da pressão a que está submetida à indústria e da resposta que dá, na forma de conduta ambiental da empresa.

Figura 04 Matriz de correlação entre a pressão da estrutura da indústria e a conduta ambiental. (Abreu, 2001)

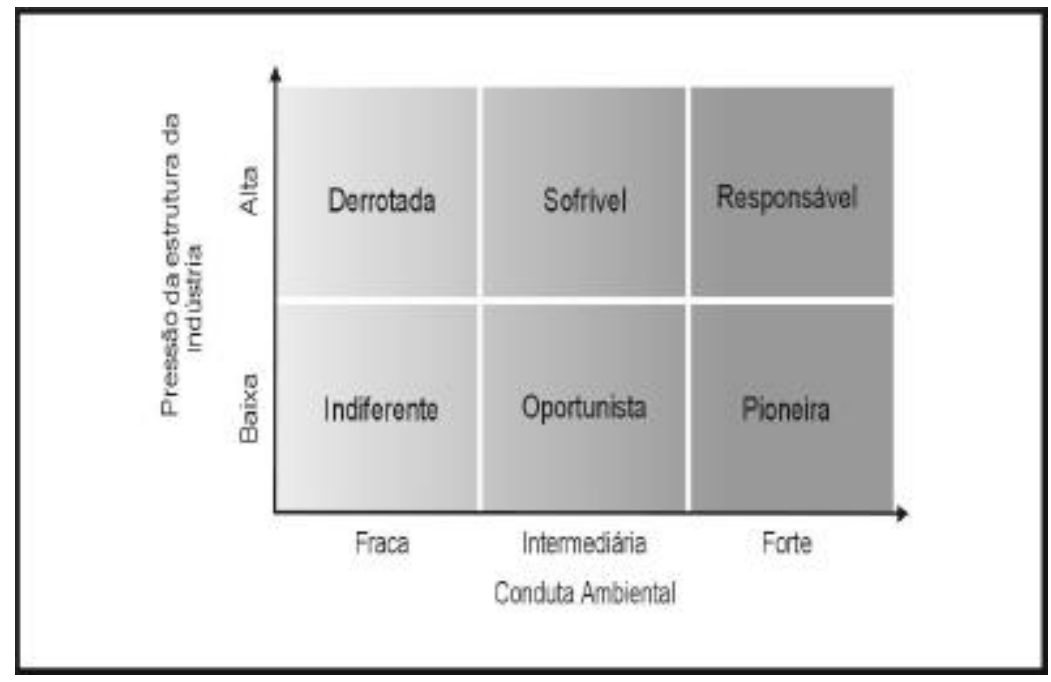

A matriz [2]x[3] estabelece "rótulos" que caracterizam o posicionamento estratégico das empresas, classificando-as, como: derrotada, sofrível, responsável, indiferente, oportunista ou pioneira. Estes "rótulos" são adequados e suficientes para definir a estratégia ambiental adotada. A matriz de correlação está estruturada nas seguintes hipóteses: 
$\Rightarrow$ As variáveis - conduta ambiental e pressão da estrutura da indústria - estão relacionadas e são elementos do modelo ECP-Ambiental fundamentais para compreender como e porque as estratégias ambientais das empresas evoluem no tempo.

$\Rightarrow$ A ocorrência de choques implica em mudanças na conduta ambiental das empresas, resultando em ajustes nos posicionamentos estratégicos definidos no modelo ECP-Ambiental.

O estudo do funcionamento da matriz de correlação permite validar as hipóteses formuladas. Quando uma empresa que está sujeita a uma alta pressão da estrutura da indústria e adota uma conduta ambiental fraca revela-se uma empresa derrotada, com elevados riscos associados com a performance ambiental. Por outro lado, quando uma empresa está submetida a altas pressões da estrutura da indústria e atua com uma conduta ambiental intermediária é considerada uma empresa sofrível com relação à estratégia ambiental.

As empresas com uma conduta ambiental forte submetidas a altas pressões da estrutura da indústria atuam de forma responsável, buscando alcançar uma performance ambiental superior com vantagens competitivas. O significado de empresa indiferente advém de uma empresa submetida a baixas pressões da estrutura da sua indústria e que responde com uma conduta ambiental fraca, ou seja, a variável ambiental não influencia na definição da estratégia da empresa.

Esse posicionamento é dinâmico, o que implica que a ocorrência de choques pode mudar o posicionamento ambiental estratégico. Por exemplo, acidentes ambientais que resultam em modificações no comportamento da sociedade e podem fazer com que uma empresa passe de um posicionamento "indiferente" para "derrotada".

Por outro lado, quando uma empresa está sub metida a baixas pressões da estrutura da indústria e passa a adotar uma conduta intermediária, a empresa assume um posicionamento de forma oportunista em busca da vantagem competitiva, que as outras empresas concorrentes já alcançaram. Finalmente, as empresas que atuam sob uma baixa pressão são consideradas pioneiras se adotarem uma conduta ambiental forte.

As empresas pioneiras percebem desde cedo as vantagens competitivas e agem agressivamente para explorá-las. Essas empresas são as primeiras a colher os frutos decorrentes da melhoria da imagem, de um maior controle do processo e da redução de custos inerentes a prevenção da poluição. Porter (1999) ressalta que as primeiras empresas a agir transformam inovações em vantagens sustentáveis. A inovação em si pode ser copiada, mas as outras vantagens competitivas perduram ao longo do tempo.

Analisando a conduta ambiental de cada uma das empresas pesquisadas e fazendo uma correlação com a pressão ambiental da indústria obtém-se o posicionamento ambiental estratégico. Abreu et al (2002) observaram que cinco empresas petroquímicas adotam uma conduta ambiental forte e duas possuem uma conduta intermediária. Considerando que as pressões ambientais da indústria petroquímica são altas, conclui-se que cinco empresas adotaram um posicionamento responsável e duas revelaram um posicionamento sofrível, entretanto, nenhuma delas posicionou-se derrotada.

Por outro lado, Abreu et al (2002) revelaram uma conduta fraca em cinco empresas têxteis e quatro de bebidas. Considerando as baixas pressões ambientais das indústrias têxteis e de bebidas, essas empresas são indiferentes às questões ambientais. Duas empresas têxteis e uma de bebidas posicionaram-se como oportunistas, pois estavam assumindo uma conduta ambiental intermediária. Somente uma empresa têxtil apresentou-se como pioneira, resultado de uma conduta forte, apesar da baixa pressão da estrutura da indústria. 
O Modelo ECP-Triplo responde a necessidade de representar a indústria atuando em um mercado aberto e sujeita a pressões de ordem econômica, social e ambiental. Nesse sentido, a variável ambiental se encaixa no modelo ECP-Ambiental, permitindo inferir a performance ambiental da empresa, a partir da análise da conduta dos participantes, submetidos às pressões de mercado em que operam.

O uso do modelo ECP- ambiental como uma ferramenta para a tomada de decisão inicia-se com a definição da conduta ambiental da empresa, que pode ser fraca, intermediária ou forte, dependo do seu posicionamento frente aos indicadores. Tendo sido determinada a conduta ambiental da empresa, devem ser determinadas quais são as pressões da estrutura da indústria definidas a partir das características ambientais: legislação ambiental, impacto ambiental e exigências ambientais das partes interessadas. A combinação dessas características vai determinar se a pressão da estrutura da indústria é alta ou baixa.

A combinação entre a conduta ambiental e a pressão da estrutura da indústria resulta em uma matriz [2]x[3] que permite determinar, facilmente, seu posicionamento ambiental e a estratégia a ser adotada para que a empresa mude de posicionamento. Tomando como base a matriz, é possível comparar a situação da empresa com os seus concorrentes submetidos às mesmas pressões da estrutura da indústria.

O modelo ECP-Ambiental possibilita a análise e a comparação de empresas em indústrias e, principalmente, possibilita a identificação de perfis de comportamento. Os resultados encontrados mostram que empresas pertencentes ao mesmo setor industrial, e, por conseguinte, sujeitas às pressões ambientais similares, podem ser classificadas em diferentes posicionamentos ambientais estratégicos, revelando a existência de condutas ambientais diferenciadas entre as empresas. Os resultados obtidos demonstram também a existência de estruturas diferenciadas entre as indústrias.

O uso do modelo ECP-Ambiental contribui, portanto, para que as empresas avaliem, de forma simples, seu posicionamento estratégico atual e definam qual a posição que desejam ocupar. Além disso, considerando que todo o posicionamento é relativo, o modelo induz às empresas a estabelecerem comparações com os seus principais competidores, ou entre unidades de negócios distintas na mesma empresa. Da mesma forma, a empresa pode fazer a comparação com empresas reconhecidas como modelos de excelência ambiental.

\section{REFERÊNCIAS BIBLIOGRÁFICAS}

ABREU, Mônica, C. S. Modelo de Avaliação da Estratégia Ambiental: Uma Ferramenta para a Tomada de Decisão. Tese (Doutorado em Engenharia de Produção) - Programa de Pós-Graduação em Engenharia de Produção, Universidade Federal de Santa Catarina, Florianópolis, 2001.

ABREU, Mônica, C. S.; FIGUEIRÊDO, Jr. Hugo, S.; VARVAKIS, Gregório. Modelo de Avaliação da Estratégia Ambiental: Os Perfis de Conduta Estratégica. READ Edição Especial 30 Gestão Ambiental e Competitividade na Empresa, Vol. 8, n. 6, dezembro de 2002.

AGUIAR, Danilo R. D. A Indústria de Esmagamento de Soja no Brasil: Mudança Estrutural, Conduta e Alguns Indicadores de Desempenho. R. Econ. Sociol. Rural, Brasília. V. 732. n. 1, p. 23-46. Jan./Mar. 1994. 
ASSOCIAÇÃO BRASILEIRA DE NORMAS TÉCNICAS - ABNT. Sistemas de Gestão Ambiental-Especificações e diretrizes para uso: NBR ISO 14001. São Paulo: ABNT, out. 1996.

ASSOCIAÇÃO BRASILEIRA DA INDÚSTRIA QUÍMICA - ABIQUIM. Atuação Responsável. Disponível em <URL: http://abiquim.com.html>[12/11/2001].

COPELAND, Tom., KOLLER, Tim., MURRIN, Jack. Avaliação de Empresas - Valuation. São Paulo: MAKRON Books do Brasil, 2000.

ELKINGTON, Jonh. Cannibals with Forks: The triple bottom line of $21^{\text {st }}$ century business. Canada: NSP, 1998.

ELKINGTON, John. Petroleum in the $21^{\text {st }}$ century: The triple bottom line: implications for the oil industry. Oil \& Gas, v. 97, n. 50, dez. 1999.

KETOLA, Tarja. Why don't the Oil Companies Clean Up their Act? The Realities of Environmental Planning. Long Range Planning, v. 31, n. 1, p. 108-119, 1998.

MURRAY, Jones G.; HARTOG, Jan J.; SKYES, Richard M. Environmental performance indicators - The line and management tool. Int. Conf. Health Safety Envir. Oil Gas Explor. Prod., Society of Petroleum Engineers (SPE), Richardson, TX, (USA), v. 2, p. 537-545, 1996.

A NATUREZA Paga o Preço da Discórdia no Setor. Brasil Energia, n. 246, maio 2001, p. 42.

NORCIA, Vicent di. Environmental and Social Performance. Journal of Business Ethics, v.15, n. 7, pp. 773-784, 1996.

ORGANISATION for Economic Co-Operation and Development - OECD. Towards Sustainable Development: Environmental Indicators. Paris: OECD, 1998.

PORTER, Michael. E. Competitive Strategy. New York: The Free Press, 1980.

PORTER, Michael E. Competição. On Competition: Estratégias Competitivas Essenciais. Rio de Janeiro: Campus, 1999.

RODRIGUEZ, Miguel Ángel; RICART, Joan Enric. Dirección Medioambiental de la Empresa. Barcelona: Gestión 2000, 1998.

SCHERER, F. M.; ROSS, David. Industrial Market Structure and Economic Performance. 3. Ed. Boston: Houghton Mifflin, 1990.

SCHERER, F. M. Industry Structure, Strategy and Public Policy. New York: Harper Collins, 435 p., 1996.

VASCONCELOS, F. C. e CYRINO, A. B. Vantagem Competitiva: Os Modelos Teóricos Atuais e a Convergência entre Estratégia e Teoria Organizacional. RAE - Revista de Administração de Empresas, V.40, n.4, p.20-37, Out/Dez, 2000.

WHITAKER, M. Emerging "Triple Bottom Line" Model for Industry Weights Environmental, Economic, and Social Considerations. Oil \& Gas, v. 97, n. 51, 1999.

Artigo recebido em 10.02.2004. Aprovado em 21.01.2004. 


\section{Mônica Cavalcanti Sá de Abreu}

Professora Adjunta da Faculdade de Economia, Administração, Atuarias e Contabilidade (FEAAC)

- Universidade Federal do Ceará - UFC. Doutora em Engenharia de Produção pela EPS/UFSC.

E-mail: mabreu@ufc.br

Interesses de pesquisa: Gestão ambiental, estratégia, qualidade, competitividade.

Endereço: Depto. de Administração - Av. da Universidade, 2853 -Fortaleza-CE, 60020-181.

\section{Gregório Jean Varvakis Rados}

Professor Adjunto, Centro de Ciências da Educação - Departamento de Biblioteconomia e Documentação da UFSC. Doutor em Engenharia de Produção - Loughborough University, Inglaterra.

Interesses de pesquisa: Estratégia, competitividade, inovação, gestão da informação, qualidade.

E-mail: grego@eps.ufsc.br

Endereço: Rua Liberato Carioni, 250, Lagoa da Conceição - Florianópolis-SC, 8062-205.

\section{Hugo Santana de Figueiredo Junior}

Consultor de Empresas - PLANNER Consultoria. Master in Business Administration- Rensselaer Polytechnic Institute, Troy, NY - Estados Unidos.

Interesses de pesquisa: Estratégia, competitividade, inovação.

E-mail: planner@baydenet.com.br

Endereço: Rua Andrade Furtado, 1601- apto. 700 - Fortaleza-CE, 60190-070. 